Revista Brasileira de Agricultura Irrigada v.9, nº.5, p.287 - 291, 2015

ISSN 1982-7679 (On-line)

Fortaleza, CE, INOVAGRI - http://www.inovagri.org.br

DOI: $10.7127 /$ rbai.v9n500306

Protocolo 306.15 - 24/05/2015 Aprovado em 11/09/2015

\title{
AVALIAÇÃO DA UMIDADE DO SOLO EM FUNÇÃO DA PRESENÇA DE MATÉRIA ORGÂNICA E COBERTURA DO SOLO NO CULTIVO DA ALFACE CRESPA (Lactuca sativa L.)
}

\author{
Diego Bispo dos Santos Farias ${ }^{1}$, Ariovaldo Antonio Tadeu Lucas ${ }^{2}$, Maria Aparecida Moreira ${ }^{3}$, Luís \\ Fernando de Andrade Nascimento ${ }^{4}$, José Carlos Freitas de Sá Filho ${ }^{5}$
}

\begin{abstract}
RESUMO
A alface é uma das hortaliças mais exigentes em água, sendo seu déficit um fator limitante para a produção desta olerícola. O objetivo do trabalho foi avaliar a influência de diferentes tipos de cobertura do solo na umidade do solo. Para tanto foi escolhida a cultivar Babá de Verão. O trabalho foi desenvolvido em área experimental localizada no Campus Rural, que fica a $15 \mathrm{~km}$ da Universidade Federal de Sergipe. O delineamento utilizado foi de blocos casualizados com três repetições, sendo os tratamentos compostos de três tipos de cobertura (plásticos: preto, preto e branco, preto e prata) e testemunha sem cobertura, todos com e sem adubação, totalizando 8 tratamentos. Foram instalados tensiômetros para a realização da avaliação da tensão de água no solo. Os resultados mostraram que a umidade manteve-se dentro do limite adequado para a cultura da alface quando utilizou-se cobertura no solo.
\end{abstract}

Palavras-chaves: hortaliça, manejo de água e solo, mulching

\section{SOIL MOISTURE EVALUATION IN FUNCTION OF ORGANIC MATTER PRESENCE AND GROUND COVER IN LETTUCE GROWTH (Lactuca sativa L)}

\footnotetext{
ABSTRACT

The lettuce crop is one of the most vegetables that requires water, and its deficit is a limiting factor to produce this vegetable. This work aimed to evaluate the influence of different types ofcover soil in the soil moisture. Thus,it chose a summer cultivate. The study was carried out in experimental field of the Rural Campus, which is $15 \mathrm{~km}$ from the Federal University of Sergipe. The design was a randomized complete block design with three replications, and the treatments composed of three types of coverage (Plastic: black, black and white, black and silver) and control without coverage, all with and without fertilizer, totaling eight treatments. Tensiometers were installed to carry out the assessment of water stress in thesoil. The results showed that moisture was maintained within the appropriate limits for the culture of lettuce was used as ground cover.

${ }^{1}$ Acadêmico de Eng. Agronômica - Universidade Federal de Sergipe. E-mail: diegotrust@gmail.com

${ }^{2}$ Professor Doutor do Departamento de Engenharia Agrícola - Universidade Federal de Sergipe. E-mail: aatlucas@gmail.com

${ }^{3}$ Professora Doutora do Departamento de Engenharia Agronômica - Universidade Federal de Sergipe. E-mail: hij47@hotmail.com

4 Acadêmico de Eng. Agronômica - Universidade Federal de Sergipe. E-mail: luiz.fer.nando@hotmail.com

${ }^{5}$ Acadêmico de Eng. Agronômica - Universidade Federal de Sergipe. E-mail: carlos.freitassa@yahoo.com.br
} 
Keywords: vegetable, water and soil management, mulching

\section{INTRODUÇÃO}

A alface é uma das hortaliças folhosa mais consumida no país e no mundo (SANTOS et al., 2001). A fácil aquisição do produto, sabor, qualidade nutritiva e baixo custo são características que favorecem o consumo (COMETTI et al., 2004). O consumidor tem se tornado mais exigente, havendo necessidade de produzir a alface em quantidade e com qualidade, bem como manter o seu fornecimento o ano todo (OHSE et al., 2001). Em razão dessa grande demanda que se faz necessário o estudo e o desenvolvimento de técnicas que facilitem o seu manejo e, por consequência, que diminuam seu custo de produção.

A técnica da cobertura do solo, também conhecida como "mulching", associada à proteção de plantas com polipropileno, pode ser uma alternativa viável para melhorar a produtividade e a qualidade da alface (REGHIN et a., 2002).

Além disso, a cobertura retém a água no solo mantendo-o mais tempo úmido e, assim, é possível aumentar os intervalos entre irrigações. Atua, também, como agente isolante, impedindo oscilações bruscas da temperatura do solo e contribuindo para a menor evaporação da água armazenada com melhor aproveitamento do conteúdo de água no solo pelas plantas (BIZARI et al., 2009). No entanto, para que a utilização da cobertura seja viável é preciso que novas alternativas de cobertura, disponíveis na região de cultivo, sejam avaliadas (SANDRI et al., 2007).

A água é um dos principais insumos que limita, mais frequentemente, o rendimento da cultura da alface, reduzindo, assim, a eficiência do sistema de produção agrícola. Torna-se necessária então, a realização de um manejo adequado da irrigação para atender às necessidades da cultura e obter maior retorno econômico (AZEVEDO et al., 2005).

Os processos fisiológicos envolvidos na produção vegetal têm uma relação muito estreita com a maior ou menor disponibilidade de água no solo para as plantas (AGUIAR, 2005).
A curva de retenção de água é um instrumento de grande importância em estudos de qualidade do solo com vistas a nortear as práticas de uso e o manejo sustentável dos sistemas de produção agrícola (MACHADO et al.,2008).

O conhecimento detalhado da dinâmica da água durante o desenvolvimento de uma cultura fornece elementos essenciais ao estabelecimento ou aprimoramento de práticas de manejo agrícola que visam à otimização da produtividade (CRUZ et al., 2005).

O presente trabalho teve como objetivo avaliar o comportamento da alface, em função de diferentes tipos de cobertura do solo, alternando com e sem adubação orgânica.

\section{MATERIAL E MÉTODO}

Este trabalho foi conduzido no município de São Cristóvão-SE, nas seguintes coordenadas geográficas: $11^{\circ} 01^{\prime} \mathrm{S}$; $37^{\circ} 12^{\prime} \mathrm{W}$. e altitude $20 \mathrm{~m}$.

Para o experimento foi utilizada a cultivar Babá-de-verão. As mudas foram produzidas em casa de vegetação onde foram utilizadas bandejas plásticas com 150 células e substrato base de pó de coco, mantendo as bandejas em ambiente protegido, o sistema de irrigação utilizado foi o gotejamento, até que apresentassem quatro folhas definitivas, quando foram transplantadas para os canteiros.

$O$ delineamento experimental utilizado foi o de blocos casualizados com fatorial $4 \times 2$, sendo oito tratamentos e três repetições num total de 24 parcelas, constituídos pelos diferentes tipos de cobertura: plástico preto e branco, preto e prata, preto, e sem cobertura (testemunha) e alternando com matéria orgânica e sem matéria orgânica.

A irrigação foi realizada pela manhã e a tarde. A umidade do solo foi monitorada com 12 tensiômetros colocados em cada tratamento, na profundidade de $20 \mathrm{~cm}$.

Após o preparo dos canteiros e transplantio das mudas foram instalados os tensiômetros. 
Para as leituras foi utilizado um tensímetro digital. As leituras foram realizadas diariamente no período da manhã, antes da primeira irrigação.

Foram coletadas amostras indeformadas de solo, na mesma profundidade em que os tensiômetros foram instalados, para isso foi utilizado o coletor de amostras indeformadas tipo Uhland, cada anel com dimensões de 0,02m de altura e $0,05 \mathrm{~m}$ de diâmetro. As amostras foram levadas ao laboratório de Física do Solo da Universidade Federal de Sergipe para a determinação das características físicas do solo.

As amostras indeformadas foram utilizadas para obtenção da curva de retenção que relaciona o teor ou o conteúdo de água no solo com a força (tensão) com que está retida pelo mesmo. Para elaboração da curva de retenção utilizaram-se as tensões $-0,-4,-6,-10,-33$, e $-1200 \mathrm{kPa}$. Para tensões de -4 a $-10 \mathrm{kPa}$ foi utilizada mesa de tensão. Câmaras de baixa tensão foram usadas para o ponto $33 \mathrm{kPa}$ e de alta tensão para oponto1200 kPa. As amostras foram mantidas tanto na mesa de tensão como nas câmaras de pressão pelo tempo necessário para atingir o equilíbrio, ou seja, o momento em que não mais houvesse drenagem de água. $\mathrm{O}$ ajuste das curvas de retenção da água no solo se deu com base na equação de Van Genuchten (1980), utilizando o programa CURVARET versão 2.16 (Departamento de Agricultura - ESALQ), e plotados em função das tensões de sucção aplicadas.

A)

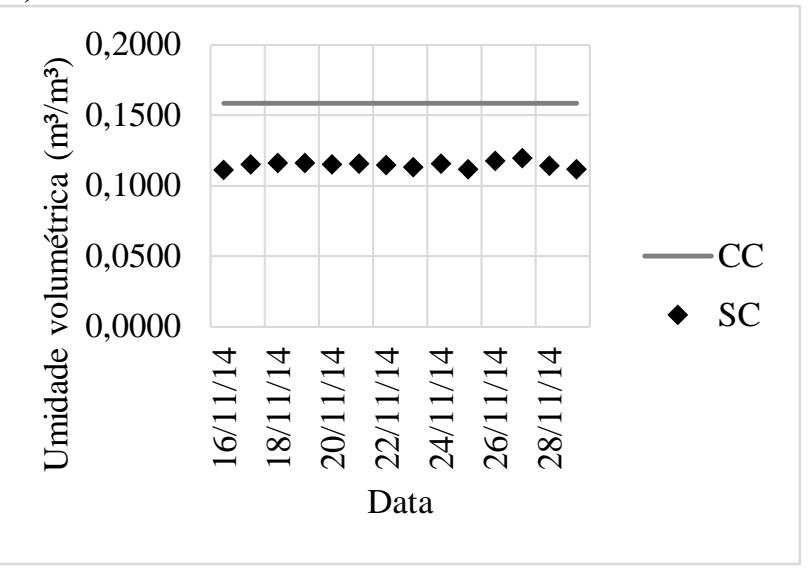

\section{RESULTADOS E DISCUSSÕES}

Em relação a tensão de água no solo houve variação em relação aos tratamentos estudados, entretanto existiu uma tendência dos tratamentos com cobertura do solo apresentarem leituras menores, havendo assim, uma influência da cobertura na tensão de água no solo e por consequência na umidade volumétrica do solo.

Santos e Pereira (2004) observaram que para alface americana quanto menor a tensão de água no solo maior foi a matéria fresca da parte comercial, destacando a importância do fornecimento de água visto que a maior produtividade foi encontrada quando as irrigações foram distribuídas com maior frequểncia ao longo do ciclo da cultura.

O manejo da irrigação deve ser feito com o intuito de repor ao solo a quantidade de água retirada pela cultura, ou seja, nesse trabalho como as umidades dos tratamentos com cobertura permaneceu próximas à capacidade de campo, isso salienta a importância do uso de técnicas que trazem benefícios à produção agrícola e economia no uso da água, pois podese diminuir o número de irrigações durante o ciclo da cultura.

$\mathrm{Na}$ figura 1, observa-se que ao utilizar cobertura do solo os valores de umidade ficaram próximos a capacidade de campo, sendo que os melhores valores de umidade foram observados no tratamento com plástico preto, evidenciando assim que o uso da cobertura no solo foi propício a melhor retenção de água no solo. Por outro lado, o tratamento sem cobertura permaneceu com valores abaixo da capacidade de campo.

Oliveira et al., (2005) em trabalho com cobertura do solo determinaram que o solo sem cobertura morta apresentou menores valores de umidade quando comparado ao solo coberto, devido à exposição da superfície do solo.

B)

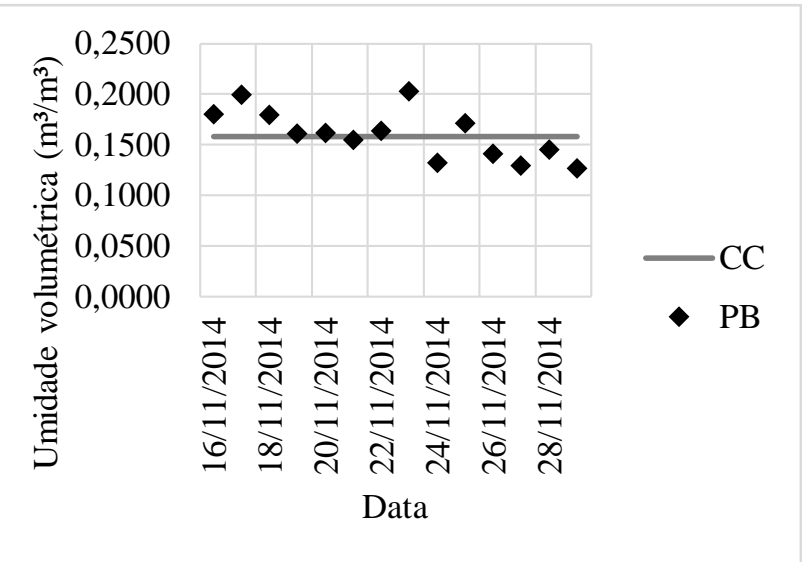


C)

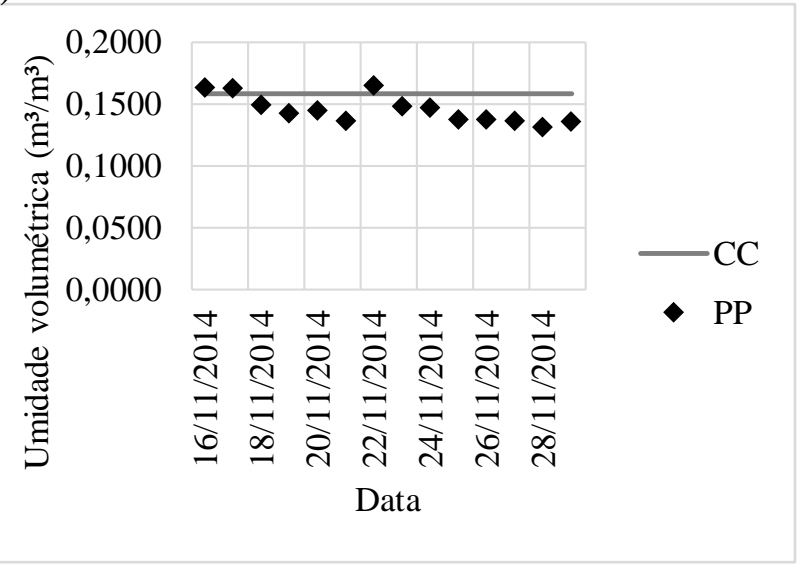

D)

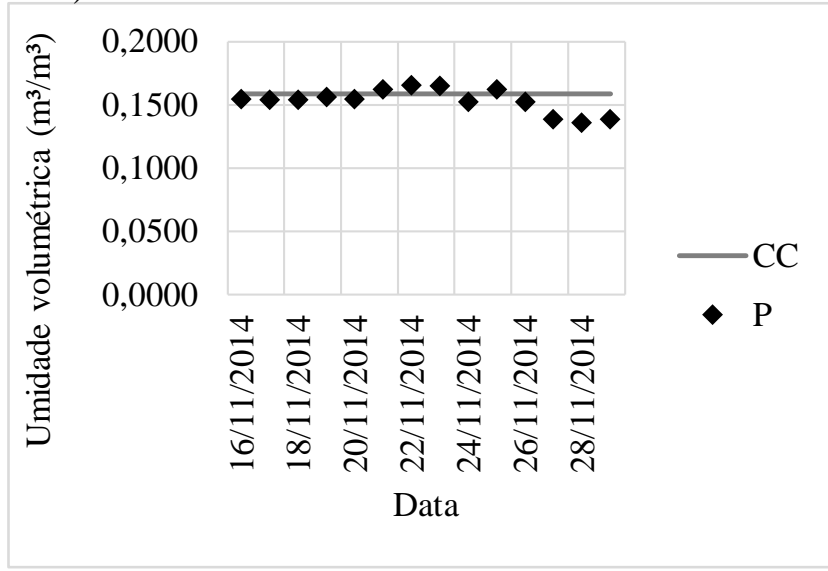

Figura 1: Valores de umidades em função dos dias, nos tratamentos sem cobertura (A), com cobertura plástica preta e branca (B), preta e prata (C) e plástico preto (D).

\section{CONCLUSÃO}

Os resultados permitiram concluir que, o uso da cobertura do solo mantém a umidade próxima a capacidade de campo, ideal para atingir a produção máxima das culturas.

\section{REFERENCIAS BIBLIOGRÁFICAS}

AGUIAR, J.V.de. A Função de Produção na Agricultura Irrigada. Fortaleza: Imprensa Universitária, 2005.196p.

AZEVEDO, B. M. de; BASTOS, F. G. C.; VIANA, T. V. de A.; RÊGO, J. de L.; D’ ÁVILA, J.H. T. Efeitos de níveis de irrigação na cultura da melancia.

Revista Ciência Agronômica, Vol.36, No .1 , jan.-abr., 2005: 9- 15.

BIZARI, D. R.; MATSURA, E. E.; ROQUE, M. W.; SOUZA, A. L. de. Consumo de água e produção de grãos do feijoeiro irrigado em sistemas plantio direto e convencional. Ciência Rural, v. 39, n. 7, p. 2073-2079, out, 2009.

COMETTI, N. N.; Composto nitrogenado e açucares solúveis em tecidos de alface orgânica, hidropônica e convencional. Horticultura Brasileira, v. 22, n. 4, p. 748-753, 2004.
CRUZ, A. C. R.; LIBARDI, P. L.; CARVALHO, L. A.; ROCHA, G. C. Balanço de água no volume de solo explorado pelo sistema radicular de uma planta de citros. Revista Brasileira de Ciência do Solo, 29:1-10, 2005.

MACHADO, J. L.; TORMENA, C. A.; FIDALSKI, J.; SCAPIN, C. A. Inter-relações entre as propriedades físicas e os coeficientes da curva de retenção de água de um Latossolo sob diferentes sistemas de uso. Revista Brasileira de Ciência do Solo, 32:495-502, 2008.

REGHIN, M. Y. ;PURISSIMO, C.; FELTRIM, A. L.; FOLTRAN, M. A. Produção de alface utilizando cobertura do solo e Proteção das plantas. Scientia Agraria, v.3, n.1-2, p.69-77, 2002.

OLIVEIRA, M. L. de; RUIZ, H. A.; COSTA, L. M. da; SCHAEFER, C. E. G. R. Flutuações de temperatura e umidade do solo em resposta à cobertura vegetal. Revista Brasileira de Engenharia Agrícola e Ambiental, v.9, n.4, p.535-539, 2005.

OHSE, S.; DOURADO NETO, D.; MANFRON, P.A.; SANTOS, O. S. Qualidade de cultivares de alface produzidos em hidroponia. Scientia Agrícola, v. 58, n. 1, p. 181-185,jan./mar. 2001. 
SANTOS, S. R.; PEREIRA, G. M. Comportamento da alface tipo americana sob diferentes tensões da água no solo, em ambiente protegido. Engenharia Agrícola, v.24, n.3, p.569-577, set./dez. 2004.
SANTOS, R. H. S.; SILVA, F.; CASALI, V. W. D.; CONDE, A. R. Efeito residual da adubação com composto orgânico sobre o crescimento e produção de alface. Pesquisa Agropecuária Brasileira, v. 36, n. 11, p. 1395-1398, 2001. 